\title{
LABORATORY DIAGNOSIS OF HELICOBACTER PYLORI INFECTION IN ENDOSCOPIC BIOPSY SAMPLES OF DYSPEPTIC PATIENTS- A HOSPITAL-BASED DIAGNOSTIC ACCURACY STUDY
}

\author{
Kumar Ratnesh', Deotale Vijayashri ${ }^{2}$, Jain Jyoti ${ }^{3}$, Gangane Nitin ${ }^{4}$, Mendirata Kr. Deepak ${ }^{5}$, Narag Pratibha ${ }^{6}$
}

${ }^{1}$ Senior Resident, Department of Microbiology, IGIMS, Patna.

2 Professor, Department of Microbiology, MGIMS, Sewagram, Wardha.

3 Professor, Department of Medicine, MGIMS, Sewagram, Wardha.

${ }^{4}$ Professor, Department of Pathology, MGIMS, Sewagram, Wardha.

5 Professor, Department of Microbiology, MGIMS, Sewagram, Wardha.

${ }^{6}$ Professor, Department of Microbiology, MGIMS, Sewagram, Wardha.

\begin{abstract}
\section{BACKGROUND}

The identification of the clinical consequences of Helicobacter pylori (H. pylori) infection is certainly one of the major discoveries within the past 20 years in medicine. Dyspepsia is a very common group of symptom referring to upper gastrointestinal tract for which patients consult the physician, accounting for about $4 \%$ to $14 \%$ of their consultations. Annual Incidence of Helicobacter pylori is $6 \%-14 \%$ in developing countries with faeco-oral route of transmission. In this context, this study has been undertaken to look for the association of H. pylori in adult patients of dyspepsia with comparative evaluation of diagnostic test for detection of Helicobacter pylori in dyspeptic patients visiting in a tertiary hospital in a rural setup of central India.
\end{abstract}

\section{MATERIALS AND METHODS}

It was a cross sectional study involving 52 patients. After obtaining history and written informed consent, 4 antral mucosal biopsy specimens were collected along with $5 \mathrm{~mL}$ blood sample. Biopsy specimens were subjected to rapid urea test, culture in Brucella broth, Gram staining and histopathological examination. subculture from Brucella broth was done on Brucella chocolate agar with \& without antibiotics. Identification was done by standard tests. Serum was separated and used for ELISA test for H. pylori IgG antibody.

\section{RESULTS}

Out of the 52 patients studied, 25 (48.07\%) were positive by Rapid Urease Test (RUT), 20 (38.46\%) by Gram staining, 17 (32.69\%) by Culture, 21 (40.38\%) by Histopathology, and 28 (53.84\%) by H. pylori IgG antibody by ELISA test. RUT had 100\% sensitivity and 77.14\% specificity, while histopathology had $94.11 \%$ sensitivity and $85.14 \%$ specificity and $H$. pylori IgG antibody had $94.11 \%$ sensitivity and $65.71 \%$ specificity in reference to culture.

\section{CONCLUSION}

In our study, we have revealed that for diagnosing of $H$. pylori one can use RUT for rapid diagnosis in the endoscopic room itself and confirm diagnosis by culture.

\section{KEYWORDS}

Helicobacter Pylori (H. Pylori), Dyspepsia, Antral Biopsy Sample, Rapid Urease Test (RUT), Brucella Broth, Brucella Chocolate Agar, Toluidine Blue.

HOW TO CITE THIS ARTICLE: Ratnesh K, Vijayashri D, Jyoti J, et al. Laboratory diagnosis of Helicobacter pylori infection in endoscopic biopsy samples of dyspeptic patients- A hospital-based diagnostic accuracy study. J. Evolution Med. Dent. Sci. 2017;6(52):3951-3954, DOI: 10.14260/Jemds/2017/855

\section{BACKGROUND \\ The identification of the clinical consequences of Helicobacter pylori (H. pylori) infection is certainly one of the major discoveries within the past 20 years of medicine. H. pylori was the first formally recognised bacterial carcinogen and is one of the most common human pathogen. It has been aetiologically associated with gastritis and gastric associated diseases, peptic ulcer, gastric adenocarcinoma and primary}

Financial or Other, Competing Interest: None.

Submission 12-05-2017, Peer Review 16-06-2017,

Acceptance 22-06-2017, Published 29-06-2017.

Corresponding Author:

Ratnesh Kumar,

Senior Resident,

Department of Microbiology,

IGIMS, Patna.

E-mail:drkrat@gmail.com

DOI: $10.14260 /$ jemds $/ 2017 / 855$ gastric carcinoma. ${ }^{1}$ Dyspepsia is a very common human experience for which there are numerous causes. Dyspepsia is the group of symptoms which refers to the upper gastrointestinal tract for which patients consult the physician, accounting for about $4 \%$ to $14 \%$ of their consultations. However, the prevalence of dyspepsia in the general population is much higher, with $20 \%-30 \%$ patients experiencing dyspeptic symptoms and with many of them self-medicating themselves. ${ }^{2}$ Until the discovery of $H$. pylori, the physicians and microbiologists believed that the stomach was likely to be sterile because of the presence of its acid 'milieu'. The successful isolation of spiral Gram-negative bacilli by them has changed the focus from a non-infectious to an infectious aetiology i.e. from $\mathrm{pH}$ to $\mathrm{Hp} .^{3} \mathrm{H}$. pylori infection is now a particular concern in developing countries. It colonizes $70 \%$ to $90 \%$ of the population whereas it is $50 \%$ in developed countries. ${ }^{2}$ The prevalence of infection varies both between and within countries in relation to race, ethnicity 
and geographical area of the populations. This has been attributed to the poor socioeconomic status, unhygienic practice and overcrowding condition. The accepted routes of its transmission are the faeco-oral route in the developing countries and the Oro-oral route (through the saliva) in the developed countries. ${ }^{4}$ Today the role of $H$. pylori has been established in chronic antral gastritis, duodenal ulcers, chronic gastric ulcers, dyspepsia, gastric cancer and gastric lymphoma. The World Health Organization has added $H$. pylori to its list of known carcinogens. ${ }^{5}$ Currently there are many diagnostic tests for detection of infection with this organism, but there is no commonly acknowledged "gold standard" method for diagnosing $H$. pylori infection. In this context this study has been undertaken to look for the association of $H$. pylori in adult patients of dyspepsia with comparative evaluation of diagnostic test for detection of $H$. pylori in dyspeptic patients visiting in a tertiary hospital in a rural setup of central India.

\section{MATERIALS AND METHODS}

This was a hospital based cross sectional study carried out from January 2011 to June 2012 after obtaining permission from the institutional ethical committee. Patients of both sexes and age group of 15 yrs. or above, diagnosed to have dyspepsia as per clinical history were recruited as the study subjects. Patients with history of PPI, $\mathrm{H}_{2}$ receptor antagonist, warfarin, fluoxetine, steroid use within one week before endoscopy, Antibiotic use within four weeks before endoscopy, severe medical illness and active gastrointestinal bleeding were excluded from the study. After obtaining the informed written consent, the patients enrolled for this study. Patients were instructed to report to the endoscopic unit on an empty stomach. 4 Antral biopsies were collected from each patient with an Olympus Fibro-optic Video-gastro-endoscope under local anaesthesia $(10 \%$ Xylocaine). Upper gastrointestinal endoscopy was performed under aseptic precautions. One biopsy sample was put into urea broth, another one biopsy was transported in Brucella broth for culture and Gram staining and two biopsy samples were submitted for histopathological analysis in $10 \%$ formal saline. $5 \mathrm{~mL}$ blood samples were collected by taking aseptic precaution. The separated serum was divided into small aliquots and these were properly labelled and stored at $-70^{\circ} \mathrm{C}$ to be processed collectively for ELISA for IgG against $H$. pylori later.

\section{Rapid Urease Test}

A biopsy tissue from antrum was placed in $0.5 \mathrm{~mL}$ to $1 \mathrm{~mL}$ $10 \%$ fresh urea broth with positive and negative control and incubated at $37^{\circ} \mathrm{C}$, the broth was examined after every 30 minutes for $4 \mathrm{hrs}$. A colour change from yellow to red or magenta was read as positive.

\section{Culture}

The biopsy samples were collected and transported to the laboratory in Brucella broth. Samples were processed within $1 \mathrm{hr}$. Subculture from Brucella broth was done on Brucella chocolate agar with antibiotics (Polymyxin-B, Amphotericin B \& Vancomycin) and without antibiotics. Incubated plates and Brucella broth vials were incubated in candle jar with burning of candle at $37^{\circ} \mathrm{C}$. Lawn culture of ATCC E. coli on
MacConkey agar was used to maintain microaerophilic condition. Sterile cotton soaked in sterile water was used to create $90-100 \%$ humidity. The culture plates and broth culture vials were first examined for H. pylori after $72 \mathrm{hrs}$., followed by every $24 \mathrm{hrs}$. for 7 days. The isolated colonies of H. pylori were subcultured in liquid broth (Brucella broth) and solid media (Brucella chocolate agar) with antibiotics (Polymyxin-B, Amphotericin B \& Vancomycin) and also without antibiotics. The appearance of turbidity in liquid medium was taken as indicator of growth. Purity of the growth was checked by Gram staining, Oxidase, Catalase, Rapid Urease Test (RUT) and sub culture was done on solid medium (Brucella agar) and incubating in aerobic and microaerobic conditions.

\section{Direct Gram Staining}

The smears were prepared on clean, grease free slides from the tissue homogenate which was fixed with $95 \%$ ethanol, by putting 2-3 drops of it on the slide and allowing them to evaporate. The smears which were thus prepared were stained by using Jensen's modification of Gram staining, but instead of using Saffranin, dilute Carbol fuchsin $(0.2 \%)$ was used as a counter stain, which helped in the better visualization of Gram negative bacteria.

\section{Histopathology}

The biopsy specimens which were collected in $10 \%$ formal saline as a fixative were transported to the pathology laboratory after proper labelling and with the requisition form for the Toluidine blue staining. After this, they were observed and reported by the pathologists.

\section{ELISA H. Pylori IgG Antibody}

The Demeditec H. pylori IgG ELISA kit was used. All the serum samples which were stored at $-70^{\circ} \mathrm{C}$ were thawed and all the test procedures were carried out according to the manufacturer's instructions. Titres above the cut-off value of $10 \mathrm{U} / \mathrm{mL}$ were noted as positive.

Results were analysed on the basis of number (Percentage) of culture positive and positive by other diagnostic methods for $H$. pylori. Validity (Accuracy) of rapid urease test (RUT), Gram staining, histopathology and ELISA IgG antibody were compared with culture in terms of sensitivity, specificity.

\section{RESULTS}

The present study was conducted in the Department of Microbiology in collaboration with Pathology and Medicine in a tertiary hospital in a rural setup of central India.

Amongst the enrolled patients, males 29/52 (55.76\%) were predominant for dyspepsia. Majority of the study population were in the age group from 25 - 55 years, with $53.84 \%$ patients belonging to lower socioeconomic class and $59.6 \%$ patients belonging to nearby village i.e. rural area.

\begin{tabular}{|c|c|c|}
\hline Tests Performed & Positive & Percentage \\
\hline Culture & 17 & $32.69 \%$ \\
\hline Direct Gram Smear & 20 & $38.46 \%$ \\
\hline RUT & 25 & $48.07 \%$ \\
\hline Histopathology & 21 & $40.38 \%$ \\
\hline H. pylori IgG antibody & 28 & $53.84 \%$ \\
\hline \multicolumn{2}{|c|}{$\begin{array}{c}\text { Table 1. Diagnostic Methods for the } \\
\text { Diagnosis of H. pylori (N=52) }\end{array}$} \\
\hline
\end{tabular}




\begin{tabular}{|c|c|c|}
\hline Tests & Sensitivity & Specificity \\
\hline Direct Gram stain & $94.11 \%$ & $88.57 \%$ \\
\hline RUT & $100 \%$ & $77.14 \%$ \\
\hline Histopathology & $94.11 \%$ & $85.14 \%$ \\
\hline H. pylori IgG antibody & $94.11 \%$ & $65.71 \%$ \\
\hline \multicolumn{2}{|c|}{ Table 2. Sensitivity and Specificity of } \\
tests in respect to Culture \\
\hline
\end{tabular}

\section{DISCUSSION}

The method of detection of $H$. pylori infection varies from hospital to hospital. It depends on various factors which add to the isolation of organism. ${ }^{6}$ In the present study, we had lower isolation of $H$. pylori compared to other hospitals' studies as we used the criteria for $H$. pylori isolation was culture positive. The prevalence of $H$. pylori infection has varied in different countries depending upon the environmental, host, laboratory detection, patient selection, socioeconomic status and age. Currently many different diagnostic tests exist for detecting $H$. pylori infection. Each test has its own merits and demerits in term of indication, sensitivity, specificity, cost and time. Many different protocols have been used to detect $H$. pylori in biopsy samples. As per protocol it includes urease test, histology, microscopy, culture and PCR. The present study was undertaken to compare the different diagnostic methods, with both invasive and noninvasive techniques for detection of $\mathrm{H}$. pylori infection in patients with dyspepsia.

A total of 52 patients were included in this study, with a mean age 38 years [Range 18-70 years]. Among these patients, $55.76 \%$ were male while $44.24 \%$ were female. Similar findings were found in a study which was done in India by Navin Chandra Motiram Kaore et al and Ahmed et al who also observed the active age group of 20 to $40 \mathrm{yrs}$. to be more vulnerable, as was also observed in our study. ${ }^{7,8}$ Out of 52 dyspeptic patients, $53.84 \%$ belonged to lower socioeconomic class, $26.93 \%$ to middle class and only $19.23 \%$ belonged to higher class. About $60 \%$ study populations belonged to rural area. High rates of infection have been associated with low socioeconomic status, Broutet et al and Fernando et al.9,10

Culture of the biopsy specimens cannot be used routinely as it is time consuming and also very difficult to maintain the strict anaerobic measures. However, the bacterial culture surely yields better results and provides information about the specific antibiotics which is to be used for eradication of the bacteria in different patients keeping in view the development of resistance. Culture is the gold standard for the detection of $H$. pylori infection. ${ }^{11,12}$ Although the method is difficult, time consuming and usually gives false negative results, it is a prerequisite for further characterisation of the organisms as antibiotic resistance. The sensitivity of culture varied from $90 \%$ to $97 \%$ reported by various workers like Marshall et al, Jones et al and Goodwin et al.12,13,14 They had used Trypticase Soy agar, Brain Heart Infusion agar, Skirrow agar and Brucella agar supplemented with $10 \%$ whole sheep blood. The Indian studies had reported using these medias, sensitivity varies from $1.09 \%$ to $63 \%$. In the present study, 17 $(32.69 \%)$ of patients were positive by Culture, in spite of using Brucella chocolate agar with selective agents like (Polymyxin B, Amphotericin B and Vancomycin). The low rate of isolation may be because of the fastidious nature of $H$. pylori and because of a number of factors like the patchy distribution of the organism, inadequate mincing of the biopsy material and the loss of viability of the specimen during transportation. Hence, these factors are difficult to control.

Considering culture as the gold standard, the sensitivity of the RUT is $100 \%$, specificity $77.14 \%$, Positive predictive value $68 \%$ and negative predictive value $100 \%$. In comparison to Javed Yakoob et al, Vandana Berry et al, and N Sadeghifard et al sensitivity, our sensitivity was higher but specificity lower. 15,16,17 About 5-10\% patients have lower urease activity due to lower number of $H$. pylori which cannot detect by RUT. Various modification of urease test has been done to increase the sensitivity of the test. However, simple and cheap in house urease test medium giving similar results as that of commercial kit of rapid urease tests. The sensitivity of the test depends on the $\mathrm{pH}$ of the medium, concentration of urea, indicator used and temperature of incubation. RUT gives much fast result when compared with histology and culture. This has an advantage of giving positive result to the clinician in the endoscopic room.

Serology may reduce the endoscopic intervention as it is an invasive procedure. Serology helps in establishing and monitoring the therapeutic effect of antimicrobial treatment for the eradication of $H$. pylori as well as for screening in epidemiological studies. 28/52 samples were positive (53.48\%) for IgG against H. pylori by this ELISA based test. Kullavanijaya $\mathrm{P}$ et al reported 120/191 patients to be positive i.e. $62.8 \%$, with a sensitivity of $96.8 \%$ and a specificity of $96.8 \%$, while Abida Malik et al reported a seropositivity of $58.3 \%{ }^{18}$ Daad $\mathrm{H}$ Akbar et al reported $73 \%$ patients to be positive for IgG. Our positivity rate of $53.48 \%$ was comparable to that which was reported by all the authors.

Histology has been used as a diagnostic tool for H. pylori. Various stains like haematoxylin and eosin, Giemsa, Gram, 1\% methylene blue, Warthin Starry silver method and fluorescent stains. ${ }^{19}$ As per current recommendations, Giemsa staining is the best stain, as it is cheap, less time consuming and diagnostic yield is increased as compared to other staining procedures. Barry J. Marshall advocates "If the H. pylori diagnosis is going to make an important contribution to management, then the most sensitive test should be used." This is in conformity with our observation that histology (Giemsa staining) detected most of the infected patients who underwent gastroscopy in our study. Histology, in addition to detection of the organisms, also helps in establishing the diagnosis of associated gastritis (if present) in the biopsy specimen. In this study, histological evidence of $H$. pylori was recorded in 21 (40.38\%) of patients. Several reports were published before this study that showed sensitivities and specificities of histological sections for detection of $H$. pylori $95 \%$ and $99 \% .^{20}$ In the present study, the sensitivity and specificity of smear examination are $94.11 \%$ and $85.14 \%$ respectively.

\section{CONCLUSION}

In our study, we have revealed that for diagnosing $H$. pylori one can use RUT for rapid diagnosis in the endoscopic room itself and confirm diagnosis by culture.

\section{Limitation of Study}

For this research study, we have used the most common and easily available methods to diagnose $H$. pylori due to money constraints. We could not evaluate many expensive medias to 
grow the $H$. pylori for better isolation. We were unable to do Urea breath test in our study though it is highly specific due to the same constraints.

\section{REFERENCES}

[1] Warren JR, Marshall BL. Unidentified curved bacilli on gastric epithelium in active chronic gastritis. Lancet 1983;321(8336):1273-5.

[2] Kate V, Ananthakrishnan N, Badrinath S, et al. Prevalence of helicobacter pylori infection in disorders of the upper gastrointestinal tract in South India. Natl Med J India 1998;11(1): 5-8.

[3] Ahmed KS, Khan AA, Ahmed I, et al. A prevalence study to elucidate the transmission pathways of Helicobacter pylori at oral and gastroduodenal sites of a south Indian population. Singapore Med J 2006;47(4):291-6.

[4] Sonnenberg A, Everhart JE. The prevalence of selfreported peptic ulcer in the United States. Am J Public Health 1996;86(2):200-5.

[5] Blaser MJ, Perez-Perez GI, Kleanthous H, et al. Infection with Helicobacter pylori strains possessing cagA is associated with an increased risk of developing adenocarcinoma of the stomach. Cancer Res 1995;55(10):2111-5.

[6] Kullavanijaya P, Thong-Ngam D, Hanvivatvong O, et al. Analysis of eight different methods for the detection of the helicobacter pylori infection in patients with dyspepsia. J Gastroenterol Hepatol 2004;19(12):13926.

[7] Kaore NM, Nagdeo NV, Thombare VR. Comparative evaluation of the diagnostic tests for helicobacter pylori and dietary influence for its acquisition in dyspeptic patients: a rural hospital based study in central India. Journal of Clinical and Diagnostic Research 2012;6(4):636-41.

[8] Akbar DH, Eltahawy ATA. Helicobacter pylori infection at a university hospital in Saudi Arabia: prevalence and comparison of the diagnostic modalities and the endoscopic findings. Indian J Pathol Micr 2005;48(2):181-5.
[9] Broutet N, Sarasqueta AM, Sakarovitch C, et al. Helicobacter pylori infection in patients consulting gastroenterologists in France: prevalence is linked to gender and region of residence. Eur J Gastroenterol Hepatol 2001;13(6):677-84.

[10] Fernando N, Holton J, Vaira D, et al. Prevalence of Helicobacter pylori in Sri Lanka as determined by PCR. J Clin Microbiol 2002;40(7):2675-6.

[11] Hazell SL, Evans DJ, Graham DY. Helicobacter pylori catalase. J Gen Microbiol 1991;137(1):57-61.

[12] Goodwin CS, Blincow ED, Warren JR, et al. Evaluation of cultural techniques for isolating Campylobacter pyloridis from endoscopic biopsies of gastric mucosa. J Clin Pathol 1985;38(10):1127-31.

[13] Marshall BJ, Royce H, Annear DI, et al. Original isolation of Campylobacter pyloridis from human gastric mucosa. Microbios Lett 1984;25(28):83-8.

[14] Schaub N, Stalder H, Stalder GA, et al. Campylobacter pylori, gastritis and ulcer disease. Microbiological, histological and serological studies. Schweiz Med Wochenschr 1988;118(9):293-301.

[15] Yakoob J, Jafri W, Abid S, et al. Role of rapid urease test and histopathology in the diagnosis of Helicobacter pylori infection in a developing country. BMC gastroenterology 2005;5:38.

[16] Berry V, Sagar V. Rapid urease test to diagnose helicobacter pylori infection. JK Science 2006;8(2):868.

[17] Sadeghifard N, Aslani MM, Ghasemi A. Comparison of different laboratory methods for diagnosis of Helicobacter pylori. J Bio Scien 2006;6(6):1146-9.

[18] Malik A, Singhal S, Mukharji U. Evaluation of an ELISA based antibody test against $\mathrm{H}$. pylori in cases of nonulcer dyspepsia. J Med Microbiol 1999;17(3):137-9.

[19] Anim JT, Al-Sobkie N, Prasad A, et al. Assessment of different methods for staining Helicobacter pylori in endoscopic gastric biopsies. Acta histochemica 2000;102(2):129-37.

[20] Vakil N, Rhew D, Soll A, et al. The cast-effectiveness of diagnostic testing strategies for Helicobacter pylori. The American Journal of Gastroenterology 2000;95(7):1691-8. 